\title{
Underreporting of traffic injuries involving children in Japan
}

\author{
S Nakahara, S Wakai
}

\begin{abstract}
Background-Significant underreporting of road traffic injuries by the police has been documented, even in developed countries. The objective of this study was to clarify the magnitude of underreporting of police data in Japan.

Methods-Police reports were compared with those of the fire department and the Marine and Fire Insurance Association of Japan.

Results-The results reveal significant underreporting by police of child vehicle occupant injuries. The true incidence of these injuries in preschoolers was twice as high as that provided by official police reports.

Conclusion-Police reports would underestimate the magnitude of vehicle occupant injuries in children and distort any evaluations of preventive initiatives. Improving the police report system, and establishing a more comprehensive trauma registry, that would include data from hospitals and insurance companies should be implemented.

(Injury Prevention 2001;7:242-244)
\end{abstract}

Department of

International

Community Health,

Graduate School of

Medicine, University

of Tokyo, Japan, Hongo

7-3-1, Bunkyo-ku,

Tokyo 113-0033, Japan

S Nakahara

S Wakai

Correspondence to: Dr Nakahara

shinji@m.u-tokyo.ac.jp

Keywords: underreporting; traffic; occupant injuries

Motor vehicle occupant injuries in children are rapidly increasing in Japan due to increased passenger car ownership and vehicle kilometers traveled. ${ }^{1}$ According to the traffic accident statistics (TAS) compiled by the National Police Agency, preschoolers' passenger morbidity rate was 48.3 per 100000 in 1985 and reached 121.7 per 100000 in 1997 (fig 1). The

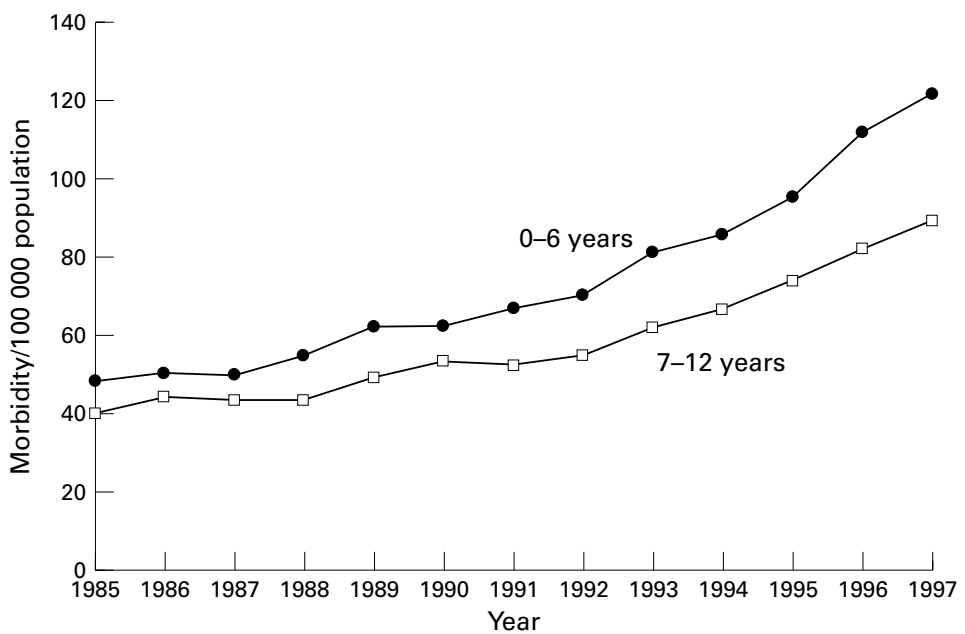

Figure 1 Trend of child motor vehicle occupant injury, fapan 1985-97 (based on published data by the National Police Agency). mortality rate, however, remained stable: ranging from 0.51 in 1985 to 0.44 in 1997. To tackle this increasing health hazard, the Japanese government enacted the Child Restraint Law in April 2000

The TAS are the only available detailed data source that includes non-fatal road traffic injuries. It is on these data that policymaking, evaluation, and research on traffic injuries and safety measures have been based. Injury monitoring systems based on hospital records are not yet available in Japan.

Previous studies comparing police data and hospital records in other countries have revealed significant underreporting in police data, even in developed countries where good reporting systems exist. ${ }^{2-6}$ Minor injuries are more likely to be underreported. Thus, motor vehicle occupant morbidity is likely to be underreported because many occupant injuries are minor. To clarify the magnitude of underreporting involving children in Japanese police data, we compared these data to other sources.

\section{Methods}

The police data were derived from TAS in 1997 compiled by the National Police Agency. These statistics include all cases reported by the police officers attending vehicle crash scenes. Officers are expected to register all traffic injuries requiring medical treatment. Cases transferred to hospitals by ambulance were obtained from the Annual Report of Ambulance and Rescue in 1997 compiled by the Fire Defense Agency. The number of cases that received insurance reimbursement incurred by medical examinations and/or treatments was derived from the Marine and Fire Insurance Association of Japan. Insurance companies' reports include traffic accidents between 1 April 1997 and 31 March 1998 all of which are reported to police because police certificates are needed to receive insurance reimbursement. Drivers of single vehicle collisions, crashes between vehicles insured by mutual aid associations, or crashes between uninsured vehicles were not included in the data of the insurance companies.

Table 1 Comparative data of road traffic injuries: police $v$ fire department, 1997

\begin{tabular}{lccc}
\hline Age (years) & $\begin{array}{l}\text { Police } \\
\text { (A) }\end{array}$ & $\begin{array}{l}\text { Fire department } \\
\text { (B) }\end{array}$ & A/B \\
\hline $0-6$ & 25113 & 29090 & 0.86 \\
$7-17$ & 91175 & 87205 & 1.05 \\
$18-64$ & 762993 & 513317 & 1.49 \\
$\geqslant 65$ & 89284 & 78094 & 1.14 \\
Total & 968565 & 707706 & 1.37 \\
\hline
\end{tabular}


Table 2 Comparative data of road traffic injuries: police v insurance companies, 1997

\begin{tabular}{|c|c|c|c|c|c|c|c|c|c|}
\hline \multirow[b]{2}{*}{ Age (years) } & \multicolumn{3}{|l|}{ Total } & \multicolumn{3}{|c|}{ Pedestrians and bicyclists } & \multicolumn{3}{|c|}{ Vehicle occupants } \\
\hline & $\begin{array}{l}\text { Police } \\
\text { (A) }\end{array}$ & $\begin{array}{l}\text { Insurance } \\
\text { (B) }\end{array}$ & $A / B$ & $\begin{array}{l}\text { Police } \\
\text { (A) }\end{array}$ & $\begin{array}{l}\text { Insurance } \\
\text { (B) }\end{array}$ & $A / B$ & $\begin{array}{l}\text { Police } \\
(A)\end{array}$ & $\begin{array}{l}\text { Insurance } \\
\text { (B) }\end{array}$ & $A / B$ \\
\hline $0-6$ & 25113 & 37496 & 0.67 & 14839 & 15598 & 0.95 & 10234 & 21320 & 0.48 \\
\hline $7-12$ & 33627 & 38224 & 0.88 & 26413 & 26312 & 1.00 & 7179 & 11268 & 0.64 \\
\hline $13-15$ & 18835 & 19946 & 0.94 & 14238 & 13878 & 1.03 & 4586 & 5291 & 0.87 \\
\hline $16-64$ & 801706 & 905651 & 0.89 & 128789 & 137938 & 0.93 & 672354 & 766240 & 0.88 \\
\hline$\geqslant 65$ & 89284 & 93294 & 0.96 & 41136 & 43212 & 0.95 & 48002 & 49914 & 0.96 \\
\hline Total & 968565 & 1094611 & 0.88 & 225415 & 236938 & 0.95 & 742355 & 854033 & 0.87 \\
\hline
\end{tabular}

Vehicle occupant injuries include passenger injuries in automobiles and occupant injuries on motorcyles. Drivers in single vehicle collisions are not included in the data of the insurance companies.

Ambulance data only include one category, traffic injuries whereas insurance data include pedestrians and occupants. By definition, pedestrians include pedestrians and cyclists, and occupants include passengers of automobiles and occupants of motorcycles. Therefore, we combined the police data in the same ways when comparing with these data and compared them by age groups. Age grouping in this study differs from customary five year groupings because of the manner in which the sources choose to report.

We did not compare mortality data of TAS with the insurance data because the criteria for inclusion of a death in TAS are not comparable with other data: they include only deaths within 24 hours of a crash whereas insurance data include deaths after 24 hours.

\section{Results}

Table 1 shows the data of the police and the fire department for fatal and non-fatal traffic injuries. The ratio of number of traffic injuries of preschoolers in the police data to that of the fire department was about 0.86 ; in the remaining three age groups the ratios exceeded 1.0 and for adults aged 18-64 years, the ratio was nearly 1.5 .

According to the comparative data between the police and the insurance companies (table 2), underreporting of vehicle occupant injuries in children was greater than for pedestrian injuries: the ratio of the police data to the insurance data was 0.48 in preschoolers. At least twice as many children as officially reported received medical examinations and/or treatments for vehicle occupant injuries, whereas the ratios of the police data to the insurance data in adults ranged from 0.87 to 0.96 . In contrast, pedestrian injuries of all age groups were not severely underreported: the ratios were nearly 1.0 (ranging from 0.93 to 1.03), including preschoolers and school age children.

\section{Discussion}

This study demonstrated higher underreporting rates for police data related to younger children, especially vehicle occupant injuries, when compared with other data sources. This result is consistent with previous studies in other countries. Agran et al estimated 10\%-20\% underreporting rates compared with hospital records. ${ }^{2}$ Harris et al showed that only $52 \%$ of injuries attended by police officers and only $9 \%$

\section{Key points}

- Underreporting of road traffic injuries by the police in Japan has been significant.

- Only half of child occupant injuries requiring medical examination or treatments were registered in police statistics.

- Underreporting may be due to arbitrarily applied registry criteria.

- Underreporting would distort evaluations and researches.

- A trauma registry system based on hospital records is needed.

of child injuries that should have been registered by police, were reported. ${ }^{3}$ In another study $79.2 \%$ of passengers and $87.7 \%$ of pedestrians who were hospitalized for their injuries were reported by police. ${ }^{6}$

Although the actual difference in child traffic injuries between the police and ambulance data seemed small, the actual number of injured children might be even greater than that reported by the fire department because people sustaining minor injuries often go to hospital by themselves.

Most underreporting of child traffic injuries involved occupant injuries. One reason why these injuries in children are less likely to appear in TAS may be that they are generally less serious than pedestrian injuries. Previous studies in other countries showed that accuracy of accident reports tend to decline with decreasing injury severity. ${ }^{3}{ }^{6}$

In Japan, attending officers have some discretion to determine if minor injuries should be registered when out-of-court settlements are achieved. Unregistered cases are treated as non-injury, non-criminal cases. Out-of-court settlements are more common in vehicle-tovehicle collisions in which drivers' responsibilities are almost equal when compared to pedestrian-vehicle collisions in which drivers' responsibilities are one sided.

Our results are contrary to some previous studies indicating higher underreporting in pedestrian injuries than in occupant injuries. ${ }^{36}$ However, the severity of the respective injuries may explain this contradiction. Lopez et al showed higher underreporting in pedestrians than in occupants after adjusting for injury severity, although occupants showed greater underreporting in univariate analysis. ${ }^{6} \mathrm{We}$ could not conduct such statistical adjustments because individual data were not available. 
Basically, the police and the insurance data systems deal with the same cases because insurance claims require police certificates; all cases included in the insurance data were reported to the police. The difference observed is most likely to have resulted from the inclusion criteria of the TAS, which could be arbitrarily applied by attending officers.

Child occupant injuries may be less severe than in adults because parents with young children may drive more carefully. Child restraints, which effectively protect children, do not however play a significant role in Japan. Currently, child restraint use rate is only $15 \% .{ }^{1}$ Exclusion of drivers in single vehicle collisions from the insurance data also reduces underreporting in adult occupant injuries. However, its effect is small because single vehicle collisions accounted for only $2 \%$ of all traffic accidents (TAS). In addition, insurance data do not include collisions of uninsured vehicles or those insured by mutual aid associations. Therefore, the actual number of injuries would be more than reported in the insurance data, resulting in greater underreporting in all age groups.

Individual crash data and regional data are not available in Japan because the traffic crash database is not open to the public. Only if such data became available would we be able to identify the characteristics of those involved in crashes but who are not included in TAS. Furthermore, regional comparisons at prefecture or municipality levels may be helpful in revealing determinants of underreporting.

\section{Implications for prevention}

Underreported data are likely to distort evaluations of prevention programs and other research. Evaluations of seat belt use efficacy, usually done by comparing case-fatality ratios between belted and unbelted occupants, could lead to underestimates if a large proportion of minor injuries or uninjured are excluded who might have been protected by seat belts. ${ }^{7}$

In Japan, police statistics are the only available data for non-fatal traffic injuries. They must, therefore, be more accurate and reliable by including all people involved in traffic accidents, children in particular, irrespective of out-of-court settlements or the severity of injury. A trauma registry based on hospital records has not yet been established in Japan. It could include accurate severity data not available to police. ${ }^{28}$ Integration of insurance data into a more comprehensive trauma database would also enhance evaluations of the economic impact of traffic injuries.

\footnotetext{
1 Management and Coordination Agency. White paper on traffic safety 1999. Tokyo, 1999

fic safety 1999. Tokyo, 1999
2 Agran P, Castillo D, Winn D. Limitation of data compiled from police reports on pediatric pedestrian and bicycle motor vehicle events. Accid Anal Prev 1990;22:361-70.

3 Harris $\mathrm{S}$. The real number of road traffic accident casualties in the Netherlands. A year-long survey. Accid Anal Prev 1990;22:371-8

4 Teanby D. Underreporting of pedestrian road accidents. BMF 1992;304:422.

5 Razzak JA, Luby SP. Estimating deaths and injuries due to road traffic accidents in Karachi, Pakistan, through the capture-recapture method. Int F Epidemiol 1998;27:86670 .

6 Lopez DG, Rosman DL, Jelinek GA, et al. Complementing police road-crash records with trauma registry data - an initial evaluation. Accid Anal Prev 2000;32:771-7.

7 Robertson LS. Injury epidemiology: research and control strategies. New York: Oxford University Press, 1998.

8 Lapidus G, Braddock M, Banco L, et al. Child pedestrian injury: a population collision and injury severity profile. $\mathcal{F}$ Trauma 1991;31:1110-15.
}

Fitness, good reflexes, and injury ...

One of Australia's fittest sportsmen and a member of the national one day cricket side was not able to leave for the matches in India in March because of a shoulder injury. Andrew Symonds told AAP "When I got home last night, I was packing and standing on an esky [Australian for portable plastic cooler] and getting some stuff from a shelf and the esky slid from underneath me and I fell and took the fall on my shoulder ..." (The Sunday Age, March 2001).

\section{Driver jailed for five years for fatal accident while using mobile phone}

A truck driver who was sending a mobile phone text message when he struck and killed a pedestrian at the side of a road was sentenced Wednesday to five years in prison in eastern England in February. The driver had already admitted causing death by dangerous driving, but denied that he was using the mobile phone in June 2000 when his truck hit 24 year old Paul Hammond, who was in a pull-off area of the road. The judge rejected that argument and decided that the phone was in use at the time of the crash (Contributed by Anara Guard).

\section{Reckless skiing conviction sends message on slopes}

Legal experts say the jail sentence handed down in February to a skier involved in a fatal accident at Vail, Colorado, ushers in a new era on the slopes. "It changes the landscape", said a trial lawyer in Denver who handles ski injury cases. "It sends a message that reckless skiing will not be tolerated and the machinery is in place to prosecute reckless skiers". The much publicized death happened in 1997 (USA Today, February 2001). 